\title{
High prevalence of hyperglycaemia and the impact of high household income in transforming Rural China
}

\author{
Chaowei Fu', Yue Chen², Fadi Wang ${ }^{3}$, Xuecai Wang ${ }^{3}$, Jiangen Song ${ }^{3}$ and Qingwu Jiang ${ }^{1 *}$
}

\begin{abstract}
Background: The prevalence of hyperglycaemia and its association with socioeconomic factors have been well studied in developed countries, however, little is known about them in transforming rural China.

Methods: A cross-sectional study was carried out in 4 rural communities of Deqing County located in East China in 2006-07, including 4,506 subjects aged 18 to 64 years. Fasting plasma glucose (FPG) was measured. Subjects were considered to have impaired fasting glucose (IFG) if FPG was in the range from 5.6 to $6.9 \mathrm{mmol} / \mathrm{L}$ and to have diabetes mellitus (DM) if FG was $7.0 \mathrm{mmol} / \mathrm{L}$ or above.
\end{abstract}

Results: The crude prevalences of IFG and DM were $5.4 \%$ and $2.2 \%$, respectively. The average ratio of IFG/DM was 2.5, and tended to be higher for those under the age of 35 years than older subjects. After adjustment for covariates including age (continuous), sex, BMI (continuous), smoking, alcohol drinking, and regular leisure physical activity, subjects in the high household income group had a significantly higher risk of IFG compared with the medium household income group (OR: 1.74, 95\% Cl: 1.11-2.72) and no significant difference in IFG was observed between the low and medium household income groups. Education and farmer occupation were not significantly associated with IFG.

Conclusions: High household income was significantly associated with an increased risk of IFG. A high ratio of IFG/DM suggests a high risk of diabetes in foreseeable future in the Chinese transforming rural communities.

\section{Background}

The World Health Organization (WHO) has estimated that more than 346 million people worldwide have diabetes today, and the number will likely double by 2030 $[1,2]$. In China, the number of people with diabetes is expected to increase from 20.8 million in 2000 to 42.3 million in 2030 [2]. The prevalence of diabetes for all age-groups worldwide was approximately $2.8 \%$ in 2000 and will be $4.4 \%$ in 2030 , with a large variation from one country to another $[2,3]$.

During the 20th century, developed countries experienced a rapid decline in deaths from infections and childhood diseases and a rapid increase in chronic noncommunicable diseases such as obesity, diabetes, and

\footnotetext{
* Correspondence: jiangqw@fudan.edu.cn

'Department of Epidemiology, School of Public Health, Fudan University; Key Laboratory of Public Health Safety, Ministry of Education, Shanghai 200032, China

Full list of author information is available at the end of the article
}

cardiovascular disease (CVD), which was associated with industrialization, mechanization, urbanization, and economic development. More recently, developing countries including China have been experiencing a similar transforming process [4-12]. Since early 1980s, mainland China has become one of these transforming societies and people have been experiencing great changes in lifestyles, living conditions, nutrition and health care, but there is a lag for people living in rural areas as compared to their urban counterparts [10-12]. High socioeconomic level indicated by income, education and occupation is generally associated with a low risk of diabetes in developed countries, although some studies has suggested no association between income or occupation and diabetes, and inverse associations were reported even in developing countries [13-20].

Along with the rapid change of economy during the past 30 years, the prevalence of type 2 diabetes mellitus (T2DM) has been increasing rapidly in urban China
C Biomed Central

(c) 2011 Fu et al; licensee BioMed Central Ltd. This is an Open Access article distributed under the terms of the Creative Commons Attribution License (http://creativecommons.org/licenses/by/2.0), which permits unrestricted use, distribution, and reproduction in any medium, provided the original work is properly cited. 
[21-24]; however, little is known for those living in rural communities which have been experiencing somewhat lagged changes during the period [25]. Deqing County in Zhejiang province had a net income per capita of 9773 RMB (1416 US \$) in 2007 for farmers, with an increase of $14.4 \%$ compared with the previous year, and the increasing rate was more than $10 \%$ on average since 2003[26]. The study examined the current status of hyperglycaemia including impaired fasting glucose (IFG) and diabetes mellitus (DM), and explored the relationship between socioeconomic status and hyperglycaemia in adults living in rural Deqing, China.

\section{Methods}

\subsection{Study site and population}

This is the baseline survey for the Rural Deqing Cohort Study, which was conducted in four rural communities in Deqing County, Zhejiang Province. The target population included all adult residents aged 18 to 64 years, with an exclusion of those who were temporary workers or university students who were not living in the county during the period from September 2006 to May 2007.

\subsection{Informed consent}

The study was approved by the Institutional Review Board of the Fudan University School of Public Health. A written informed consent was sought after a complete description of the study narrated to each subject.

\subsection{Subjects recruitment and data collection}

Data collectors were health workers who were recruited from each study site and trained by academic investigators. They visited each household in these rural communities and identified eligible study subjects based on name lists provided by local authorities. The participants were face-to-face interviewed. If eligible subjects were not at home at the visiting, they could be face-to-face interviewed at physical examination centers. The questionnaire covered the information on individuals' demographics, lifestyles, and disease history. All subjects were asked to have a physical examination including body weight and height measuremnts. They were also asked to provide a blood sample of $5 \mathrm{ml}$ next morning. Fasting plasma glucose test was performed by using glucose oxidase method within 2 hours.

Subjects were considered to have impaired fasting glucose (IFG) if fasting plasma glucose (FPG) was in the range from 5.6 to $6.9 \mathrm{mmol} / \mathrm{L}$ and to have diabetes mellitus (DM) if FPG was $7.0 \mathrm{mmol} / \mathrm{L}$ or above or they were receiving antidiabetic medications [27]. Hyperglycaemia refered to eigher IFG or DM. Farmers were those who made their living from farming at the interview and other occupations including teachers, managers, officers, staffes, workers, drivers, students, etc. were grouped into non-farmers. Household income was self-ranked by subjects as low, medium or high relative to others living in the same community. Body mass index $(\mathrm{BMI})$ was calculated: $\mathrm{BMI}=$ weight $(\mathrm{kg}) / \mathrm{height}^{2}$ $\left(\mathrm{m}^{2}\right)$. Smokers were those who continually smoked for more than 6 months and at least one cigarette per day. Alcohol drinking was defined as drinking any alcohol at least once a week. Regular leisure physical activity was defined as having physical activities for more than half an hour for at least twice a week. Physical activities at work or homework were not measured. Years of school education were also recorded.

\subsection{Data analysis}

All statistical tests were completed by using SPSS11.0 (SPSS Inc., Chicago, Illinois, USA; serial number: 3805233). Categorical variables were summarized by frequency count and corresponding percentage and continuous variables were summarized by mean and standard deviation. Chi-square test was used for categorical variables, and independent $\mathrm{t}$ test for continuous variables. In multinomial logistic regression analysis, we examined the associations of years of education, farmer occupation and household income with glycaemia status before and after adjustment for age (continuous), gender, BMI (continuous), smoking, alcohol drinking, and regular leisure physical activity. No significant interactions on a multiplicative scale were detected, and therefore, the final models included main terms only. An alpha level of $\leq 0.05$ (two sides) was considered to be statistically significant.

\section{Results}

\subsection{General characteristics}

A total of 5,898 (60\% of 9830 eligible study subjects) provided questionnaire information; of them 4,506 (76\%) had a physical examination and provided blood specimen. Overall, 46\% (42\% for men and 49\% for women, respectively) of the eligible population were included in the current analysis. Table 1 shows the characteristics of the participants by sex. There were more women than men with an average age of $46.1 \pm 10.0$ years. Majority of them received less than 9 years of school education, were farmers, believed to have medium household income, and joined the rural China cooperative medical insurance. Approximately one fifth of the participants had a BMI value of $25 \mathrm{~kg} / \mathrm{m}^{2}$ or greater. Smoking and alcohol drinking were common in men but not in women. Regular leisure physical activity was rare in both men and women.

\subsection{Hyperglycaemic prevalence}

A total of 48 subjects (1.1\%) reported having T2DM diagnosed by a physician and only 139 (3.1\%) reported 
Table 1 Characteristics of participants by gender from 4 rural communities, Deqing, China

\begin{tabular}{|c|c|c|c|}
\hline Characteristics & Men $(n=1865)$ & Women $(n=2641)$ & Statistical test for gender difference \\
\hline & Mean \pm SD & Mean \pm SD & \\
\hline Age (years) & $47.3 \pm 9.5$ & $46.6 \pm 9.6$ & $\mathrm{t}=2.56, P=0.011$ \\
\hline \multirow[t]{2}{*}{ BMI $\left(\mathrm{kg} / \mathrm{m}^{2}\right)$} & $22.6 \pm 2.7$ & $22.2 \pm 2.9$ & $t=4.60, P<0.001$ \\
\hline & No. (\%) & No. $(\%)$ & \\
\hline \multicolumn{4}{|c|}{ Years of education } \\
\hline$\leq 9$ & $998(53.7)$ & $1768(67.4)$ & $\chi^{2}=86.02, P<0.001$ \\
\hline$>9$ & $861(46.3)$ & $857(32.6)$ & \\
\hline \multicolumn{4}{|l|}{ Farmer } \\
\hline Yes & $1326(71.1)$ & 1917(72.6) & $\chi^{2}=1.20, P=0.274$ \\
\hline No & $539(28.9)$ & $724(27.4)$ & \\
\hline \multicolumn{4}{|c|}{ Household income } \\
\hline Low & 208(11.4) & 286(11.0) & $\chi^{2}=0.15, P=0.929$ \\
\hline Medium & $1487(81.5)$ & 2121(81.9) & \\
\hline High & 130(7.1) & 183(7.1) & \\
\hline \multicolumn{4}{|c|}{ Having rural cooperative medical insurance } \\
\hline Yes & $1733(96.2)$ & 2486(96.5) & $\chi^{2}=0.42, P=0.515$ \\
\hline No & $69(3.8)$ & $89(3.5)$ & \\
\hline \multicolumn{4}{|c|}{ Regular leisure physical activity } \\
\hline Yes & $42(2.4)$ & $53(2.1)$ & $\chi^{2}=0.26, P=0.607$ \\
\hline No & 1734(97.6) & 2436(97.9) & \\
\hline \multicolumn{4}{|l|}{ Alcohol drinking } \\
\hline Yes & $853(45.7)$ & $95(3.6)$ & $\chi^{2}=1168.47, P<0.001$ \\
\hline No & 1012(54.3) & 2546(96.4) & \\
\hline \multicolumn{4}{|l|}{ Smoking } \\
\hline Yes & $1183(63.5)$ & $53(2.0)$ & $\chi^{2}=2066.52, P<0.001$ \\
\hline No & $680(36.5)$ & $2576(98.0)$ & \\
\hline \multicolumn{4}{|c|}{ Body mass index $\left(\mathrm{kg} / \mathrm{m}^{2}\right)$} \\
\hline$<25.0$ & $1528(83.0)$ & 2209(84.6) & $\chi^{2}=2.70, P=0.225$ \\
\hline $25.0-$ & 291(15.8) & $368(14.1)$ & \\
\hline$\geq 30.0$ & $21(1.1)$ & $34(1.3)$ & \\
\hline
\end{tabular}

having ever been tested for blood sugars. Overall, the average level of FPG was $4.7 \pm 0.9 \mathrm{mmol} / \mathrm{L}$, ranging from 1.5 to $17.1 \mathrm{mmol} / \mathrm{L}$, with the crude prevalence of IFG and DM being $5.4 \%$ and $2.2 \%$, respectively. The age-standardised prevalences with 2000 standard China population were $4.2 \%$ for IFG and $2.1 \%$ for DM, respectively. The crude hyperglycaemic proportion increased significantly over age from $2.8 \%$ in the $18-24$ year group to $11.1 \%$ in the $55-64$ year group $\left(\chi_{\text {trend }}{ }^{2}=43.18, \mathrm{p}<\right.$ 0.001; Table 2) with no significant difference between men and women $\left(\chi^{2}=3.30, \mathrm{p}=0.192\right)$. The average ratio of IFG/DM was 2.5 overall (5.0 for 18-34 years group, 2.4 for 35-44 years group, 2.5 for $45-54$ years group and 2.3 for 55-64 years group, respectively), and was higher for those under the age of 35 years.

\subsection{Socioeconomic factors and hyperglycaemia}

As shown in Table 3, subjects with more than 9 years of education had a significantly lower crude prevalence of hyperglycaemia than those with less than 9 years of education, while the high income group had a significantly higher hyperglycaemic prevalence than the medium or low income groups. After adjustment for age, sex, BMI, smoking, alcohol drinking, and regular leisure physical activity in a multinomial logistic regression

Table 2 Crude prevalence of hyperglycaemia in adults by sex and age in rural Deqing (\%)

\begin{tabular}{ccccccc}
\hline Age (years) & \multicolumn{3}{c}{ Male } & \multicolumn{3}{c}{ Female } \\
\cline { 2 - 7 } & $\mathbf{n}$ & IFG & DM & $\mathbf{n}$ & IFG & DM \\
\hline $18-24$ & $50(2.7)$ & $3(6.0)$ & $0(0)$ & $59(2.2)$ & $0(0)$ & $0(0)$ \\
$25-34$ & $136(7.3)$ & $3(2.2)$ & $2(4.3)$ & $254(9.6)$ & $9(3.5)$ & $1(0.4)$ \\
$35-44$ & $577(30.9)$ & $20(3.5)$ & $12(2.1)$ & $888(33.6)$ & $35(3.9)$ & $11(1.2)$ \\
$45-54$ & $647(34.7)$ & $34(5.3)$ & $20(3.1)$ & $857(32.4)$ & $60(7.0)$ & $17(2.0)$ \\
$55-64$ & $455(24.4)$ & $30(6.6)$ & $12(2.6)$ & $583(22.1)$ & $50(8.6)$ & $23(3.9)$ \\
\hline Total & $1865(100.0)$ & $90(4.8)$ & $46(2.5)$ & $2641(100.0)$ & $154(5.8)$ & $52(2.0)$ \\
\hline
\end{tabular}

Abbreviations: IFG = impaired fasting glucose with a fasting glucose of 5.6 to $6.9 \mathrm{mmol} / \mathrm{L}, \mathrm{DM}=$ diabetes mellitus with a fasting glucose of $\geq 7.0 \mathrm{mmol} / \mathrm{L}$ or receiving antidiabetic medications, $\mathrm{n}=$ total numbers

Note: $\chi^{2}=3.30, p=0.192$ for the gender difference of hyperglycaemia. 
Table 3 Hyperglycaemic prevalence by socioeconomic characteristics in rural Deqing

\begin{tabular}{lcccc}
\hline Characteristics & $\mathbf{n}(\%)$ & IFG (\%) & DM (\%) & Statistical test \\
\hline Education years & & & & \\
$\quad \leq 9$ & $2766(61.7)$ & $169(6.1)$ & $66(2.4)$ & $\chi^{2}=7.60, p=0.022$ \\
$\quad>9$ & $1718(38.3)$ & $75(4.4)$ & $31(1.8)$ & $\chi^{2}=2.49, p=0.288$ \\
Farmer & & & $74(2.3)$ & \\
$\quad$ Yes & $3243(72.0)$ & $185(5.7)$ & $24(1.9)$ & $\chi^{2}=12.18, p=0.016$ \\
$\quad$ No & $1263(28.0)$ & $59(4.7)$ & $15(3.0)$ & \\
Household incomes & & & $65(1.8)$ & \\
$\quad$ Low & $494(11.2)$ & $20(4.0)$ & $8(2.6)$ & \\
$\quad$ Medium & $3608(81.7)$ & $191(5.3)$ & $98(2.2)$ & \\
$\quad$ High & $313(7.1)$ & $27(8.6)$ & $244(5.4)$ & $4506(100.0)$
\end{tabular}

Abbreviations: IFG = impaired fasting glucose with a fasting glucose of 5.6 to $6.9 \mathrm{mmol} / \mathrm{L}, \mathrm{DM}=$ diabetes mellitus with a fasting glucose of $\geq 7.0 \mathrm{mmol} / \mathrm{L}$ or receiving antidiabetic medications, $\mathrm{n}=$ total numbers

model, the adjusted odds ratio for IFG was 1.74 (95\% CI: 1.11, 2.72) in the high income group compared with the medium income group and the difference in IFG was not statistically significant between the low and medium income groups. After adjustment for covariates the relationship between years of education and IFG was no longer statistically significant (Table 4). There was no significant association between farmer occupation and DM.

\section{Discussion}

The data from the Chinese National Diabetes Survey showed that the prevalence of diabetes increased from $1.0 \%$ in 1980 to $2.5 \%$ in 1994 [21,22]. Data from a representative national survey in 2002 demonstrated that for T2DM the age-standardized prevalence was $4.5 \%$ in urban China and 1.8\% in rural China, and for IFG they were $2.7 \%$ and $1.6 \%$ [23]. The age-standardized prevalences of IFG (4.2\%) and DM (2.1\%) in rural Deqing in

Table 4 Unadjusted and adjusted odds ratios (95\% confidence intervals) as well as $p$ value for socioeconomic factors associated with hyperglycaemia in rural Deqing

\begin{tabular}{|c|c|c|c|c|c|c|c|}
\hline Hyperglycaemia & Characteristics & Unadjusted & $\mathrm{p}$ & Adjusted $^{\mathrm{b}}$ & $p^{b}$ & Adjusted $^{c}$ & $p^{c}$ \\
\hline \multirow[t]{10}{*}{$\mathrm{IFG}^{\mathrm{a}}$} & Years of education & & & & & & \\
\hline & $\leq 9$ & $1.44(1.09,1.90)$ & 0.011 & $0.90(0.65,1.24)$ & 0.517 & $0.99(0.70,1.40)$ & 0.961 \\
\hline & $>9$ & 1.00 & & 1.00 & & & 1.00 \\
\hline & Farmer & & & & & & \\
\hline & No & $1.23(0.92,1.67)$ & 0.161 & $1.08(0.79,1.49)$ & 0.620 & $1.03(0.74,1.43)$ & 0.876 \\
\hline & Yes & 1.00 & & 1.00 & & & 1.00 \\
\hline & Household income & & & & & & \\
\hline & Low & $0.67(0.41,1.12)$ & 0.124 & $0.63(0.38,1.05)$ & 0.077 & $0.74(0.45,1.21)$ & 0.229 \\
\hline & Medium & 1.00 & & 1.00 & & & 1.00 \\
\hline & High & $1.78(1.17,2.72)$ & 0.007 & $1.93(1.26,2.96)$ & 0.002 & $1.74(1.11,2.72)$ & 0.015 \\
\hline \multirow[t]{10}{*}{$\mathrm{DM}^{\mathrm{a}}$} & Years of education & & & & & & \\
\hline & $\leq 9$ & $1.36(0.88,2.09)$ & 0.166 & $0.74(0.44,1.25)$ & 0.261 & $0.93(0.54,1.59)$ & 0.787 \\
\hline & $>9$ & 1.00 & & 1.00 & & & 1.00 \\
\hline & Farmer & & & & & & \\
\hline & No & $0.82(0.51,1.31)$ & 0.404 & $1.18(0.71,1.97)$ & 0.526 & $1.10(0.66,1.84)$ & 0.723 \\
\hline & Yes & 1.00 & & 1.00 & & & 1.00 \\
\hline & Household income & & & & & & \\
\hline & Low & $1.69(0.95,2.98)$ & 0.073 & $1.59(0.90,2.83)$ & 0.111 & $1.79(0.98,3.27)$ & 0.058 \\
\hline & Medium & 1.00 & & 1.00 & & & 1.00 \\
\hline & High & $1.48(0.71,3.12)$ & 0.299 & $1.66(0.78,2.51)$ & 0.186 & $1.55(0.72,3.34)$ & 0.261 \\
\hline
\end{tabular}

Abbreviations: IFG = impaired fasting glucose with a fasting glucose of 5.6 to $6.9 \mathrm{mmol} / \mathrm{L}, \mathrm{DM}=$ diabetes mellitus with a fasting glucose of $\geq 7.0 \mathrm{mmol} / \mathrm{L}$ or receiving antidiabetic medications, $\mathrm{n}=$ total numbers

Note: ${ }^{\text {a }}$ Normal FPG as the reference category.

${ }^{\mathrm{b}}$ Adjusted for age (continuous) and sex.

c Adjusted for age (continuous), sex, BMI (continuous), smoking, alcohol drinking, and regular leisure physical activity. 
our study were comparable with those for urban China in 2002 [23] and those for rural Tianjin in 2004 [25]. Overweight and obesity is a major determinant for diabetes [28]. The prevalence of overweight/obesity and mean BMI in rural Deqing was comparable to the national average in the country $[23,24]$.

IFG or impaired glucose tolerance is associated with an increased risk of diabetes [29-35]. It has been suggested that the ratio of IGT prevalence versus diabetes mellitus prevalence may a useful indicator for future risk of type 2 diabetes [36,37]. The average ratio of IFG/ DM was markedly higher in this study compared with another study conducted in 2002 [23], and tended to be higher for those under the age of 35 years than older subjects, which may suggest a rapider increase in diabetes risk among the younger population in foreseeable future.

In developing country, adults with higher income have a higher risk of chronic diseases including diabetes, partly due to their earlier westernized transition of lifestyle and diet $[10-12,19,20]$. In China, a study reported that rapid income growth adversely affected Chinese diet quality [38]. This study provided a glimpse of current status of hyperglycaemia in those living in one richer rural region in China. High household income seemed to be a risk factor for IFG during a transforming process in rural China, which is consistent with some previous observations from developing nations $[19,20]$. High household income was also associated with an increasing risk of DM but this association was not statistically significant. In addition, although not significant, subjects with low household income had a lower risk of IFG $(\mathrm{aOR}=0.74)$, but had a higher risk of $\mathrm{DM}(\mathrm{aOR}=$ 1.74), compared with those with medium household income. Lack of statistical power may be one of possible reasons for these observations, and further studies are needed for any confirmation. After adjustment for covariates, education was no longer associated with hyperglycaemia. In rural China, people spend a large proportion of their income for food and some types of food such as meat products are more affordable for relatively wealthy people, which may explain our observation that high income but not high education was a risk factor for IFG.

There are some limitations for the study. This is a cross-sectional study and the evidence is weak for a possible causal linkage although it is not likely that poorer status of hyperglycaemia would result in higher household income. Another limitation is that less than $50 \%$ of the eligible subjects provided blood specimens. If people with perceived poor health were more likely to participate in the study, we might overestimate the hyperglycaemic prevalence. In this study, individuals who provided blood specimens, compared with participants who did not provide blood specimens, were older, less educated and heavier, and were more likely to be female and to have high blood pressure (diastolic blood pressure $\geq 90 \mathrm{mmHg}$ and/or systolic blood pressure $\geq 140$ $\mathrm{mmHg}$ or receiving antihypertensive medications). However, there were no differences in household income and regular leisure physical activity. Thirdly, FPG test instead of oral glucose tolerance test (OGTT) may underestimate the prevalence of diabetes. A fasting plasma glucose cut-off of $5.6 \mathrm{mmol} / \mathrm{L}$, however, has been found to be comparable to an OGTT cut-off of 7.8 $\mathrm{mmol} / \mathrm{L}[27,39]$. Fourthly, we used household income, which was self-ranked by the participants. People were less likely to report their income in Yuan value (80\%) compared with relative household income (98\%). There was an impression the people tended to under-report their income in Yuan value while a question on relative household income was less sensitive. In this study, selfranked relative household income was significantly but not highly correlated to average household income per capital among subjects who provided both (Spearman's correlation coefficient $=0.44, \mathrm{p}<0.001)$. Similar trends were observed when income was measured in Yuan values, but the estimates were less precise due to much smaller sample size. Fifthly, regular leisure physical activity was not common for this rural population and was not related to hyperglycaemia. Work related physical activity may be more relevant for rural people in China, which was not measured in this study. Lastly, there may be a household cluster effect but the information was not collected in this study.

\section{Conclusion}

In conclusion, the hyperglycaemic prevalence for adults living in a richer rural area was comparable to the average of Chinese urban population. An elevated ratio of IFG/DM suggests a high risk of diabetes in foreseeable future in the Chinese transforming rural communities. High household income was a risk factor for the prevalence of IFG. Intervention strategies should be developed for rural residents during the process of the rapid socioeconomic development.

\section{Competing interests}

The authors declare that they have no competing interests.

\section{Authors' contributions}

CF carried out this survey, participated in its design, performed the statistical analysis, and drafted the manuscript. YC participated in study design and was involved in revising the manuscript critically for important intellectual content. FW participated in the coordination and study design. XW participated in the coordination and 
data collection. JS participated in the coordination and data collection. QJ participated in study design and revised it critically for important intellectual content. All authors read and approved the final manuscript.

\section{Authors information}

Jiang, Qingwu MD, MPH

Professor of Epidemiology

138 Yi Xue Yuan Road

Department of Epidemiology

School of Public Health

Fudan University

Shanghai 200032, China

Tel: 862154237435

Fax: 862154237435

Email: jiangqw@fudan.edu.cn

\section{Acknowledgements}

This study was supported by Fudan Graduate Innovation Foundation (grant number EYF201019) and Shanghai Leading Academic Discipline Project (grant number B118). The authors would like to give their thanks to the health workers of the Deqing County Centre of Disease Prevention and Control and the community health centres for data collection.

\section{Author details}

'Department of Epidemiology, School of Public Health, Fudan University; Key Laboratory of Public Health Safety, Ministry of Education, Shanghai 200032, China. ${ }^{2}$ Department of Epidemiology and Community Medicine, University of Ottawa, Ottawa, Ontario K1H 8M5, Canada. ${ }^{3}$ Deqing County Centre of Disease Prevention and Control, Deqing County, Zhejiang Province, 313200, China.

Received: 29 March 2011 Accepted: 12 November 2011 Published: 12 November 2011

\section{References}

1. World Health Organization:[http://www.who.int/mediacentre/factsheets/ fs312/en/index.html]

2. Wild S, Roglic G, Green A, Sicree R, King H: Global Prevalence of Diabetes: Estimates for the year 2000 and projections for 2030. Diabetes Care 2004, 27:1047-1053.

3. Danaei G, Finucane MM, Lu Y, Singh GM, Cowan MJ, Paciorek CJ, et al: National, regional, and global trends in fasting plasma glucose and diabetes prevalence since 1980: systematic analysis of health examination surveys and epidemiological studies with 370 country-years and 2.7 million participants. Lancet 2011, 378(9785):31-40.

4. Omran AR: The epidemiologic transition: a theory of the epidemiology of population change. 1971. Milbank Q 2005, 83(4):731-757.

5. Sen K, Bonita R: Global health status: two steps forward, one step back. Lancet 2000, 356(9229):577-582.

6. Albala C, Vio F, Kain J, Uauy R: Nutrition transition in Chile: determinants and consequences. Public Health Nutr 2002, 5(1A):123-128.

7. Kosulwat V: The nutrition and health transition in Thailand. Public Health Nutr 2002, 5(1A):183-189.

8. Amuna P, Zotor FB: Epidemiological and nutrition transition in developing countries: impact on human health and development. Proc Nutr Soc 2008, 67(1):82-90.

9. Popkin BM: The nutrition transition and obesity in the developing world. J Nutr 2001, 131(3):871S-873S.

10. Liu Y, Rao K, Fei J: Economic transition and health transition: comparing China and Russia. Health Policy 1998, 44(2):103-122.

11. Du S, Lu B, Zhai F, Popkin BM: A new stage of the nutrition transition in China. Public Health Nutr 2002, 5:169-174.
12. Popkin BM, Du S, Zhai F, Zhang B: Cohort Profile: The China Health and Nutrition Survey-monitoring and understanding socio-economic and health change in China, 1989-2011. Int J Epidemiol 2010, 39(6):1435-1440.

13. Metcalf PA, Scragg RR, Schaaf D, Dyall L, Black PN, Jackson RT: Comparison of different markers of socioeconomic status with cardiovascular disease and diabetes risk factors in the Diabetes, Heart and Health Survey. N Z Med J 2008, 121(1269):45-56.

14. Maty SC, Everson-Rose SA, Haan MN, Raghunathan TE, Kaplan GA: Education, income, occupation, and the 34-year incidence (1965-99) of Type 2 diabetes in the Alameda County Study. Int J Epidemiol 2005, 34(6):1274-1281.

15. Agardh EE, Ahlbom A, Andersson T, Efendic S, Grill V, Hallqvist J, et al: Socio-economic position at three points in life in association with type 2 diabetes and impaired glucose tolerance in middle-aged Swedish men and women. Int J Epidemiol 2007, 36(1):84-92.

16. Robbins JM, Vaccarino V, Zhang H, Kasl SV: Socioeconomic status and diagnosed diabetes incidence. Diabetes Res Clin Pract 2005, 68(3):230-236.

17. Tang $M$, Chen $Y$, Krewski D: Gender-related differences in the association between socioeconomic status and self-reported diabetes. Int I Epidemiol 2003, 32(3):381-385.

18. Borrell LN, Dallo FJ, White K: Education and diabetes in a racially and ethnically diverse population. Am J Public Health 2006, 96(9):1637-1642.

19. Grant JF, Hicks N, Taylor AW, Chittleborough CR, Phillips PJ, The North West Adelaide Health Study Team: Gender-specific epidemiology of diabetes: a representative cross-sectional study. Int J Equity Health 2009, 8(1):6.

20. Zuo H, Shi Z, Hu X, Wu M, Guo Z, Hussain A: Prevalence of metabolic syndrome and factors associated with its components in Chinese adults. Metabolism 2009, 58(8):1102-1108.

21. National Diabetes Research Group: Diabetes mellitus survey of 300,000 subjects in 14 provinces and cities of China. Chin J Intern Med 1981, 20:678-681.

22. Pan XR, Yang WY, Li GW, Liu J: Prevalence of diabetes and its risk factors in China, 1994. National Diabetes Prevention and Control Cooperative Group. Diabetes Care 1997, 20:1664-1669.

23. Li LM, Rao KQ, Kong $L Z$, Yao CH, Xiang HD, Zhai FY, et al: A description on the Chinese national nutrition and health survey in 2002. Zhonghua Liu Xing Bing Xue Za Zhi 2005, 26(7):478-484.

24. Yang W, Lu J, Weng J, Jia W, Ji L, Xiao J, Shan Z, Liu J, Tian H, Ji Q, Zhu D, Ge J, Lin L, Chen L, Guo X, Zhao Z, Li Q, Zhou Z, Shan G, He J, China National Diabetes and Metabolic Disorders Study Group: Prevalence of diabetes among men and women in China. N Engl J Med 2010, 362(12):1090-1101.

25. Tian H, Song G, Xie H, Zhang H, Tuomilehto J, Hu G: Prevalence of diabetes and impaired fasting glucose among 769792 rural Chinese adults. Diabetes Res Clin Pract 2009, 84(3):273-278.

26. Deqing County Statistics Bureau. [http://www.dqzc.gov.cn/tjj/showmain. asp?tid=1552].

27. Genuth S, Alberti KG, Bennett P, Buse J, Defronzo R, Kahn R, et al: Expert Committee on the Diagnosis and Classification of Diabetes Mellitus. Follow-up Report on the Diagnosis of Diabetes Mellitus. Diabetes Care 2003, 26(11):3160-3167

28. Hartemink N, Boshuizen HC, Nagelkerke NJ, Jacobs MA, van Houwelingen HC: Combining risk estimates from observational studies with different exposure cutpoints: a meta-analysis on body mass index and diabetes type 2. Am J Epidemiol 2006, 163(11):1042-1052.

29. Gerstein HC, Santaguida P, Raina P, Morrison KM, Balion C, Hunt D, et al: Annual incidence and relative risk of diabetes in people with various categories of dysglycemia: a systematic overview and meta-analysis of prospective studies. Diabetes Res Clin Pract 2007, 78(3):305-312.

30. Wang JJ, Yuan SY, Zhu LX, Fu HJ, Li HB, Hu G, et al: Effects of impaired fasting glucose and impaired glucose tolerance on predicting incident type 2 diabetes in a Chinese population with high post-prandial glucose. Diabetes Res Clin Pract 2004, 66(2):183-191.

31. Chen KT, Chen CJ, Gregg EW, Imperatore G, Narayan KM: Impaired fasting glucose and risk of diabetes in Taiwan: follow-up over 3 years. Diabetes Res Clin Pract 2003, 60(3):177-182.

32. Rasmussen SS, Glümer C, Sandbaek A, Lauritzen T, Borch-Johnsen K: Determinants of progression from impaired fasting glucose and impaired glucose tolerance to diabetes in a high-risk screened population: 3 year follow-up in the ADDITION study, Denmark. Diabetologia 2008, 51(2):249-257. 
33. Ferrannini E, Massari M, Nannipieri M, Natali A, Ridaura RL, GonzalesVillalpando C: Plasma glucose levels as predictors of diabetes: the Mexico City diabetes study. Diabetologia 2009, 52(5):818-824.

34. de Vegt F, Dekker JM, Jager A, Hienkens E, Kostense PJ, Stehouwer CD, et al: Relation of impaired fasting and postload glucose with incident type 2 diabetes in a Dutch population: The Hoorn Study. JAMA 2001, 285(16):2109-2113.

35. Harati H, Hadaegh F, Saadat N, Azizi F: Population-based incidence of Type 2 diabetes and its associated risk factors: results from a six-year cohort study in Iran. BMC Public Health 2009, 9:186.

36. World Health Organization: Guidelines for the prevention, management and care of diabetes mellitus.[http://whqlibdoc.who.int/emro/2006/ 9789290214045_eng.pdf].

37. Dowse GK, Zimmet PZ, King H: Relationship between prevalence of impaired glucose tolerance and NIDDM in a population. Diabetes Care 1991, 14(11):968-74.

38. Du S, Mroz TA, Zhai F, Popkin BM: Rapid income growth adversely affects diet quality in China-particularly for the poor! Soc Sci Med 2004, 59(7):1505-1515.

39. Gabir MM, Hanson RL, Dabelea D, Imperatore G, Roumain J, Bennett PH, et al: The 1997 American Diabetes Association and 1999 World Health Organization criteria for hyperglycemia in the diagnosis and prediction of diabetes. Diabetes Care 2000, 23:1108-1112.

\section{Pre-publication history}

The pre-publication history for this paper can be accessed here: http://www.biomedcentral.com/1471-2458/11/862/prepub

doi:10.1186/1471-2458-11-862

Cite this article as: Fu et al:: High prevalence of hyperglycaemia and the impact of high household income in transforming Rural China. BMC Public Health 2011 11:862.

\section{Submit your next manuscript to BioMed Central and take full advantage of:}

- Convenient online submission

- Thorough peer review

- No space constraints or color figure charges

- Immediate publication on acceptance

- Inclusion in PubMed, CAS, Scopus and Google Scholar

- Research which is freely available for redistribution

Submit your manuscript at www.biomedcentral.com/submit 